\title{
Microstructure and Electrochemical Behavior of in Vitro Ti-26Nb, Ti-26Zr and Ti-26Ta Alloys Processed by Levitation Melting Technique
}

\author{
Francisco E.F. Almeida ${ }^{1}$, Renato A.C. Santana ${ }^{2}$, Severino J.G. Lima ${ }^{1}$, Shiva Prasad ${ }^{2, *}$, Rodnei M. Gomes ${ }^{1}$ \\ ${ }^{1}$ Department of Mechanical Engineering, Federal University of Paraíba, João Pessoa-PB 58059-900, Brazil \\ ${ }^{2}$ Academic Unit of Education, Federal University of Campina Grande, Cuité-PB 58175-000, Brasil
}

\begin{abstract}
This paper presents a study on microstructure, elasticity modulus and electrochemical behavior of Ti-26Nb, $\mathrm{Ti}-26 \mathrm{Zr}$ and Ti-26Ta binary alloys obtained in an induction furnace equipped with a water cooled copper crucible which can promote levitation of the moltem alloys. The microstructures and eletrochemical behavior were investigated by means of X-ray fluorescence spectroscopy, X-ray diffractometry, optical microscopy, microvickers hardness, open circuit potential, corrosion potential and polarization resistance. The results revealed that the difference in nominal chemical composition related to contamination was extremely low, which indicates that this melting technique is highly appropriate for obtaining contaminant-free titanium alloy. The addition of niobium was very favorable for obtaining near- $\beta$ alloy with a low elasticity modulus. Additionally, alloy $\mathrm{Ti}-26 \mathrm{Nb}$ presented the best corrosion resistance combined with low elasticity modulus.
\end{abstract}

Keywords Binary Titanium Alloy, Biomedical Alloys, Electrochemical Behavior

\section{Introduction}

The beginning of commercial development of titanium in the 1940s was rapidly followed by its evolution as a material for implants. The use of titanium and its alloys underwent great development during the decade of 1970. The tendency in this period was to utilize already existing materials to manufacture orthopaedic prostheses, using, for instance, the $\mathrm{Ti}-6 \mathrm{Al}-4 \mathrm{~V}$ alloy originally developed for aero spatial applications[1].

It became necessary to develop a specific class of titanium alloys class for implants because of the elevated cytotoxicity potential of vanadium and aluminum present in Ti-6Al-4V alloy. The main result of the accumulation of vanadium in the organism is irritation of the respiratory system and the absorption of aluminum can be as harmful as vanadium and its deleterious effect is associated with neurological disorders, including Alzheimer's disease and phosphorus deficiency in bones and blood, due to the combination of aluminum ions with inorganic phosphorus[2]. Currently, several research studies aim at producing more biocompatible materials combined with a low elasticity modulus, high corrosion resistance and no toxic potential[3].

Considerable attention has been given to titanium alloys

* Corresponding author:

prasad@deq.ufcg.edu.br (Shiva Prasad)

Published online at http://journal.sapub.org/materials

Copyright (C) 2012 Scientific \& Academic Publishing. All Rights Reserved with the addition of $\mathrm{Nb}, \mathrm{Zr}$ and $\mathrm{Ta}$ [4-8]. These elements belong to a group of metals that form highly stable oxide layers which act as barriers against the corrosion medium. The physiological fluids of the human body are highly aggressive and thus the stability of the oxide layer is the mandatory factor to elaborate titanium alloys with high biocompatibility[9]. The corrosion products are the main factors responsible for biocompatibility, as these can interact with the neighboring tissues or are transported through the body fluid to different organs of human body[10]. As to the manufacturing process, usually the titanium alloys are obtained by vacuum arc melting with a non-consumable tungsten electrode and a water cooled copper hearth, or by electron beam melting. In both techniques, the cast material comes into contact with the mould walls (high purity alumina), which causes mild chemical contamination.

In this study, a less conventional process is used based on the technique of melting by levitation under heating, benefits of which are contamination free as well as homogeneous nucleation. Binary alloys of Ti-Nb, Ti-Zr and Ti-Ta, were obtained by this technique, and its microstructure, elasticity modulus and electrochemical behavior were investigated.

\section{Experimental Procedures}

The ternary alloy $\mathrm{Ti}-13 \mathrm{Nb}-13 \mathrm{Zr}$ was projected and developed for orthopedic implants use due to the unique combination of high corrosion resistance and tensile strength and 
low elasticity modulus[11]. Thus, in order to perform a comparative study with this ternary alloy and within the same range of $26 \%$ amount of the complementary element this research group decided to study binary alloys of titanium with the following three different compositions: Ti-26Nb, $\mathrm{Ti}-26 \mathrm{Zr}$ and Ti-26Ta. The raw materials used were of the following purity grade: $99.85 \% \mathrm{Ti}, 99.99 \% \mathrm{Nb}, 99.98 \% \mathrm{Zr}$ and $99.9 \% \mathrm{Ta}$. The alloys were produced by levitation melting under inductive heating using a $200 \mathrm{kHz}$ frequency generator under argon atmosphere. The furnace has a $40 \mathrm{~L}$ high vacuum chamber, and it is equipped with a water-cooled copper crucible. This crucible is cone-shaped with eight grooves. This system allows casting at most $30 \mathrm{~g}$ of titanium. Due to the difficulty encountered in dissolving elements $\mathrm{Nb}$ and $\mathrm{Ta}$, the alloys were submitted to one melting and four re-fusions. All the material obtained was submitted to thermal treatment for homogenization at $900^{\circ} \mathrm{C}$ for 4 hours under controlled atmosphere of argon and to ageing at $550^{\circ} \mathrm{C}$ for 4 hours.

Composition analysis of the samples was performed in a model XRF-1800 X-ray fluorescence spectrophotometer. The phases present in the samples were studied by an X-ray diffraction with a SIEMENS D5000 diffractometer using $\mathrm{CuK} \alpha$ radiation. Microstructural analysis was performed by optical microscope, employing an Olympus BX60M reflected light microscope. Elasticity modulus was determined in a digital ultramicro durometer SHIMADZU - model DUH-W211S.

The electrochemical tests were carried out in a standard three-electrode cell. The counter-electrode consisted of a $2.00 \mathrm{~cm}^{2}$ platinum foil. The reference electrode used was a saturated calomel electrode (SCE). The working electrodes were constructed from the ingots obtained by fusion. The working area used which was exposed to the electrolyte was $1.1 \mathrm{~cm}^{2}$. The electrolyte used was an aerated Ringer solution, which was produced with the following composition: $\mathrm{Na}^{+}$ $=3.38 \mathrm{~g} / \mathrm{l} ; \mathrm{K}^{+}=0.157 \mathrm{~g} / 1 \mathrm{Cl}^{-}=5.525 \mathrm{~g} / \mathrm{l}$ and $\mathrm{Ca}^{2+}=0.0195 \mathrm{~g} / \mathrm{l}$, with a $\mathrm{pH}$ value around 5.2. The solution in this work simulates only the inorganic cellular part of the body fluid; components such as proteins, glucose, vitamins and others are excluded.

The potentiodynamic linear polarization (PLP) and electrochemical impedance spectroscopy (EIS) studies were performed by using a potentiostat (Autolab PGSTATE 30 connected to softwares GPES and FRA2) for corrosion analysis. The PLP curves were obtained with a sweep rate of $1 \mathrm{mV} / \mathrm{s}$ in a potential range $-1 \mathrm{~V}$ to $2 \mathrm{~V}$ and the impedance spectroscopy experiments were carried out at selected potentials from the PLP curves with a frequency interval of 1 $\mathrm{kHz}$ to $0.004 \mathrm{~Hz}$. All the electrochemical corrosion tests were conducted in Ringer solution at room temperature and in ambient atmosphere.

\section{Results and Discussion}

\subsection{Composition of the Alloys}

The results of experimental composition of the alloys obtained by X-ray fluorescence analysis are presented in Table 1. Analysing the results obtained, it can be verified that the percentage of the elements of alloy is close to nominal. The difference between the experimental and the nominal values should be due to the purity grade of the elements of the alloy which was not $100 \%$ and the re-fusions that contributed, even in a small amount, to the occurrence of the deposition of oxidized material in the copper crucible. It was also found, from the data presented, that the copper of the fusion crucible did not contaminate the samples, since the analysis results shown in Table 1 did not verify the existence of copper.

Table 1. Chemical composition of the alloys

\begin{tabular}{c|ccccccc}
\hline \multirow{2}{*}{ Alloy } & \multicolumn{7}{|c}{ Alloy designation (wt.\%) } \\
\cline { 2 - 8 } & Fe & Cr & Si & Nb & Ta & Zr & Ti \\
\hline Ti-26Nb & 0.06 & 0.05 & 0.03 & 26.3 & - & - & Bal. \\
Ti-26Ta & 0.03 & 0.04 & - & - & 26.1 & - & Bal. \\
Ti-26Zr & 0.05 & 0.03 & - & - & - & 26.2 & Bal. \\
\hline
\end{tabular}

\subsection{X-Ray diffraction analysis}

The diffractograms obtained from the thermally treated samples are shown in Figure 1. The diffractograms were presented for all the samples, peaks of the phases $\alpha$ (hexagonal compact) and $\beta$ (body centered cubic), different only as to intensity and number of peaks of the phases which were confirmed by the micrographs. The diffractrogams of Ti-26Nb and Ti-26Ta samples confirm what was found in the microstructural analysis of these alloys, that the amount of beta stabilizer, niobium and tantalum, was not sufficient for the formation of $\beta$ alloy alone, because in the diffractogram the peaks of phases $\alpha$ and $\beta$ are sufficiently representative. Between 38 and 40.2, the peaks can occur for the planes (002) and (101) given by the hexagonal struture, and also by plane (110) of cubic structure and despite the similarity between the diffractograms of the alloys Ti-26Ta and Ti-26Zr a clear difference has been observed within this mentioned range of $2 \theta$.

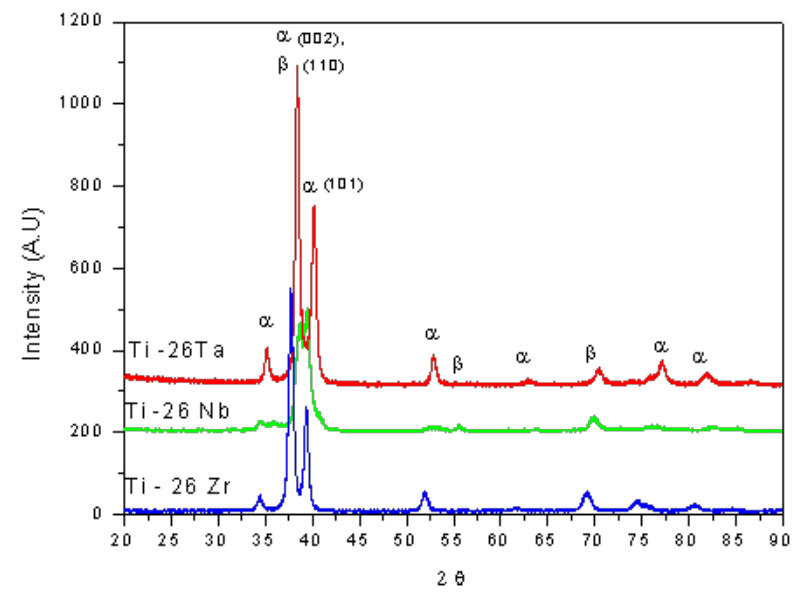

Figure 1. XRD patterns of $\alpha+\beta$ heat treated alloy at $900^{\circ} \mathrm{C}$ for $4 \mathrm{~h}$ and aged at $550^{\circ} \mathrm{C}$ for $4 \mathrm{~h}$ 
The data from X-ray diffraction cards represent values for the pure material. The addition of alloying elements dissolved in solid solution can cause distortions in the crystal lattice of the element, changing interplaner distances and, consequently, the values of the diffraction angles, which explains the slightly offset by some peaks presented in relation to reference values.

\subsection{Microstructure of the Alloys}

The three alloys were analyzed by optical microscopy and their micrographs are shown in Figure 2. The alloys Ti-26Nb, $\mathrm{Ti}-26 \mathrm{Ta}$ and $\mathrm{Ti}-26 \mathrm{Zr}$ presented microstructures where two typical phases of the alloys of $\alpha+\beta$ type coexist. The micrographs confirm the results obtained through analysis by $\mathrm{X}$-ray diffraction. It is clearly seen that the quantity of $\beta$ phase is larger than the $\alpha$ phase when the alloy studied is Ti-26Nb (Figure 2a). The alloy Ti-26Zr (Figure 2c) clearly presents the smallest percentage of $\beta$ phase, the one that was confirmed by its diffractogram. According Elias et al.[12] Ta and $\mathrm{Nb}$ have the function to be $\beta$-stabilizers, to form homogeneous solid solutions, while $\mathrm{Zr}$ acts as a neutral element for forming a homogeneous solid solution in the $\alpha$ and $\beta$ phase, the one that was confirmed by its diffractogram.

When one compares the alloys of titanium with niobium and with tantalum (Figure 2b), a much higher percentage of $\beta$ phases is seen for the alloys with niobium. According Zhou et al.[13] the Ti-Nb alloy with higher than 25 wt.\%, concentration the final microstructures will contain the retained metastable $\beta$ phase, i.e., the metastable $\beta$ phase cannot completely be transformed into $\alpha$. When the Ti-26Ta and $\mathrm{Ti}-26 \mathrm{Nb}$ alloys are compared it was observed that the niobium alloy contained more $\beta$ phase. The alloy containing $\mathrm{Ti}-26 \mathrm{Nb}$ possesses higher stability in maintaining its metastable $\beta$ phase when obtained by fusion and is cooled at room temperature in comparison to the Ti-26Ta alloy.[13]
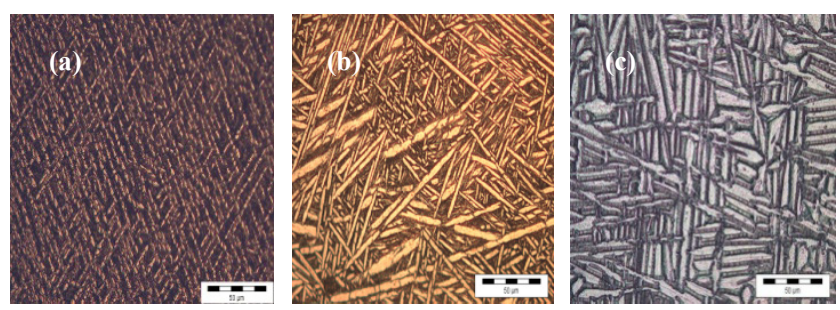

Figure 2. Optical micrographs on Ti-26Nb (a), Ti-26 Ta (b) e Ti-26Zr (c)

\subsection{Elasticity modulus of the alloys}

The results of mechanical tests for elasticity modulus determined by ultramicro durometer, are shown in Table 2. From the information in the table it is possible to compare the results obtained with alloy Ti-6Al-4V, used as biomaterial, which possesses elasticity modulus between 110 and $114 \mathrm{GPa}$. Thus, it is verified that the alloys studied presented smaller elasticity modulus values than the alloy used as implant, but they are still slightly higher than that of the human bone, whose value is between 17 and $35 \mathrm{GPa}[14]$. This reference value for the alloy $\mathrm{Ti}-13 \mathrm{Nb}-13 \mathrm{Zr}$ in the literature is in the range of $79-84 \mathrm{Gpa}[15]$. It is sufficiently noteworthy that alloy $\mathrm{Ti}-26 \mathrm{Nb}$ presents itself as the most appropriate in terms of elasticity modulus, for possible application as prostheses. The reduction of the elasticity modulus for the niobium alloy compared with the others is related to the higher percentage in volume of $\beta$ phase. The $\beta$ phase possesses a body centred cubic (BCC) structure, where the average distance between the atoms is shorter than those of the hexagonal compact $\alpha$ phase. So that if the distance is smaller, the atomic forces of attraction and repulsion will have their intensity diminished which leads to a lower elasticity modulus[16].

Table 2. Elasticity modulus of the homogenized alloys

\begin{tabular}{|c|c|}
\hline Alloys & Elasticity modulus E (GPa) \\
\hline Ti-26Nb & $51.0 \pm 0.8$ \\
\hline Ti-26Ta & $57.1 \pm 0.3$ \\
\hline Ti-26Zr & $67.7 \pm 0.4$ \\
\hline
\end{tabular}

\subsection{Corrosion test}

Electrochemical techniques to evaluate corrosion resistance are largely employed to predict the protective characteristics of some biocompatible alloys[17-19].

The open circuit potential test on the binary alloys in Ringer electrolyte is presented in Figure 3 and corrosion data extracted from the diagrams are given in Table 3 . The curves clearly show that all the alloys formed passive films spontaneously on the surface of the samples with passage of time in contact with the electrolyte. It can be observed, in the figure, that a process of active/passive transition precedes the formation of passivation film. This phenomenon may be related to modifications that occur on the working electrode surface at more negative potentials, when it is just immersed in electrolyte solution. According to Liu et al.[20], the spontaneous passivation film formed on the surface was dominated by $\mathrm{TiO}_{2}$. Similar behavior was observed by Cremasco et al.[21].

Potentiodynamic linear polarization (PLP) behavior observed for alloys $\mathrm{Ti}-26 \mathrm{Nb}$, Ti-26Ta and Ti-26Zr for corrosion resistance in Ringer solution are shown in Fig. 4. The data recorded in Table 3 confirm that alloy $\mathrm{Ti}-26 \mathrm{Nb}$ presented more noble values of corrosion potential and polarization resistance in comparison to those for alloys Ti-26Ta and Ti-26Zr. The polarization curves confirm the formation of a passivation film for all the studied alloys, the same behavior which was observed in the study of open circuit potential. Formation of the passivation film for Ti alloys is also reported by other authors[22-25]. It can also be verified from the study that alloy Ti-26Ta showed corrosion resistance similar to that obtained for the alloy Ti-26Zr. Oliveira et al.[26] observed that the titanium alloy, Ti-13Zr-13Nb, presented greater protection against corrosion compared to alloy Ti-50Zr. Karayan et al.[27], working with Ti-Ta-Nb alloys, observed that an increase in niobium and tantalum contents in alloys of titanium caused a decrease in corrosion current and turned the corrosion potential less negative. 


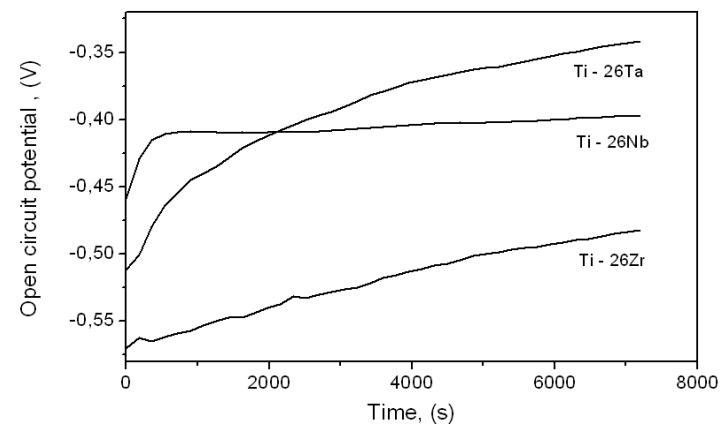

Figure 3. Open circuit potential (OCP) versus time for the titanium-based alloys in Ringer solution

Potentiodynamic linear polarization (PLP) behavior observed for alloys $\mathrm{Ti}-26 \mathrm{Nb}$, Ti-26Ta and $\mathrm{Ti}-26 \mathrm{Zr}$ for corrosion resistance in Ringer solution are shown in Figure 4. The data recorded in Table 3 confirm that alloy Ti-26Nb presented more noble values of corrosion potential and polarization resistance in comparison to those for alloys Ti-26Ta and Ti-26Zr. The polarization curves confirm the formation of a passivation film for all the studied alloys, the same behavior which was observed in the study of open circuit potential. Formation of the passivation film for Ti alloys is also reported by other authors[22-25]. It can also be verified from the study that alloy Ti-26Ta showed corrosion resistance similar to that obtained for the alloy Ti-26Zr. Oliveira et al.[26] observed that the titanium alloy, Ti-13Zr-13Nb, presented greater protection against corrosion compared to alloy Ti-50Zr. Karayan et al.[27], working with $\mathrm{Ti}-\mathrm{Ta}-\mathrm{Nb}$ alloys, observed that an increase in niobium and tantalum contents in alloys of titanium caused a decrease in corrosion current and turned the corrosion potential less negative.

Table 3. Polarization resistance obtained by electrochemical impedance spectroscopy

\begin{tabular}{|c|c|c|c|c|}
\hline & \multicolumn{4}{|c|}{ Corrosion Test } \\
\hline \multirow{2}{*}{ Alloy } & $\mathbf{O C P}$ & $\begin{array}{c}\text { Potentiodynamic } \\
\text { Polarization }\end{array}$ & Impedance \\
\cline { 2 - 5 } & $\mathbf{E}_{\text {ocp }}(\mathbf{V})$ & $\mathbf{R p}(\boldsymbol{\Omega})$ & $\mathbf{E}_{\text {corr }}(\mathbf{V})$ & $\mathbf{R p}(\boldsymbol{\Omega})$ \\
\hline $\mathrm{Ti}-26 \mathrm{Nb}$ & -0.458 & $5.552 \times 10^{5}$ & -0.385 & $4.80 \times 10^{5} \Omega$ \\
\hline $\mathrm{Ti}-26 \mathrm{Ta}$ & -0.511 & $4.354 \times 10^{5}$ & -0.538 & $2.03 \times 10^{5} \Omega$ \\
\hline $\mathrm{Ti}-26 \mathrm{Zr}$ & -0.577 & $4.144 \times 10^{5}$ & -0.627 & $1.5 \times 10^{5} \Omega$ \\
\hline
\end{tabular}

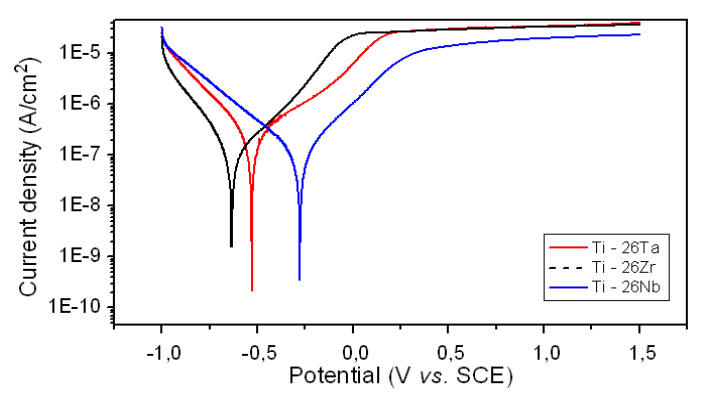

Figure 4. Potentiodynamic curves of the titanium-based homogenized alloys in Ringer solution

Electrochemical impedance spectroscopy measurements were performed in Ringer electrolyte solution to confirm the results obtained by potentiodynamic linear polarization (PLP). Nyquist diagrams obtained with the tests of electrochemical impedance spectroscopy are shown in Figure 5.
Alloy Ti-26Nb showed higher impedance as compared with that of the other alloys; consequently it has higher corrosion resistance. It was observed that the alloy of Ti containing $\mathrm{Nb}$ possesses greater polarization resistance $\left(\mathrm{R}_{\mathrm{p}}\right)$. A similar result was obtained by Assis et al. in their study[28]. The results obtained by potentiodynamic polarization and impedance studies were similar since both of them confirmed that alloy $\mathrm{Ti}-26 \mathrm{Nb}$ is more resistant to corrosion. According to Pham et al.[24] this behavior can be associated with its microstructure, which possesses an $\alpha+\beta$ type phase, favoring the formation of a spontaneous passivation film and thus displacing a corrosion potential for more noble values.

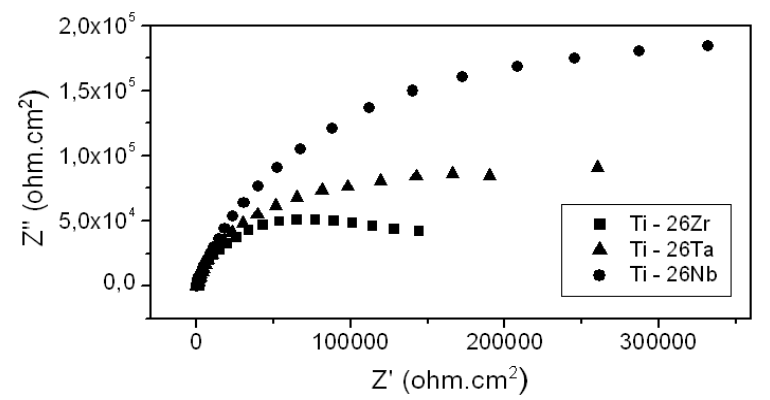

Figure 5. Nyquist diagram for the titanium-based homogenized alloys studied in Ringer solution

\section{Conclusions}

A study on microstructure, elasticity modulus, electrochemical behavior of the binary alloys Ti-26Nb, Ti-26Ta and Ti-26Zr, obtained in a magnetic induction furnace under argon atmosphere equipped with a water-cooled copper crucible, was performed in this work. The main conclusions are:

- Chemical composition loss and contaminations were extremely low. The analysis of the micrographs indicated that the fusions were efficients, since fusion damages such as unfused metals and cracks were not verified, which indicates that this fusion technique is highly indicated to obtain the titanium alloys for use as biomaterials.

- Addition of $\mathrm{Nb}$ is highly favorable for obtaining the $\alpha+\beta$ alloy with low elasticity modulus, the factor which is also necessary for its application as biomaterial.

- All the alloys studied presented excellent corrosion resistance, yet alloy $\mathrm{Ti}-26 \mathrm{Nb}$ presented the best resistance results.

- The alloy $\mathrm{Ti}-26 \mathrm{Nb}$ as a better choice when compared to $\mathrm{Ti}-13 \mathrm{Nb}-13 \mathrm{Zr}$ alloy for possible application as a biomaterial.

- Based on the above conclusions, alloy Ti-26Nb can be considered the most appropriate for use as biomaterial among all the alloys studied in this work.

\section{ACKNOWLEDGEMENTS}

The Authors gratefully acknowledge the grants received from REMULT, CAPES, CNPq and FINEP for performing this study. 


\section{REFERENCES}

[1] J. Cohen, Biomaterials in Reconstructive Surgery, 6, 135, 1983.

[2] M. Long, H.J. Rack, Titanium Alloy in Total Joint Replacement - a Materials Science Perspective. Biomaterials, 19, 1621, 1998.

[3] V.A.R. Henriques, C.R.M. Silva. Production of Titanium Alloys for Medical Implants by Powder Metallurgy. Advanced Powder Technology Key Engineering Materials, 443, 189, 2001.

[4] G. Yang, T. Zhang, Phase transformation and mechanical properties of the $\mathrm{Ti}_{50} \mathrm{Zr}_{30} \mathrm{Nb}_{10} \mathrm{Ta}_{10}$ alloy with low modulus and biocompatible. Journal of Alloys and Compounds, 392, 291, 2005.

[5] D. Kuroda, M. Niinomi, M. Morinaga, Y. Kato, T. Yashiro, Design and mechanical properties of new $\beta$ type titanium alloys for implant materials. Materials Science \& Engineering, A: Structural Materials: Properties, Microstructure and Processing, 243, 244, 1998.

[6] S. Li, Y. Hao, R. Yang, Y. Cui, M. Niinomi, Effect of Nb on microstructural characteristics of Ti-Nb-Ta-Zr alloy for biomedical applications. Materials Transactions, 43, 2964, 2002.

[7] Y. Okasaki, E. Gotoh, Mater. Implant Applications of Highly Corrosion-Resistant Ti-15Zr-4Nb-4Ta Alloy. Materials Transactions, 43, 2943, 2002.

[8] M. Greetha, A.K. Singh, A.K. Gogia, R. Asokamani, J. Effect of thermomechanical processing on evolution of various phases in $\mathrm{Ti}-\mathrm{Nb}-\mathrm{Zr}$ alloys Journal of Alloys and Compounds, 384, 131, 2004.

[9] G. Zorn, A. Lesman, I. Gotman, Oxide formation on low modulus $\mathrm{Ti} 45 \mathrm{Nb}$ alloy by anodic versus thermal oxidation. Surface and Coatings Technology, 201, 612, 2006.

[10] S.H. Teoh, Fatigue of biomaterials: A review. International Journal of Fatigue (Special Issue on Biomaterials), 22, 825, 2000 .

[11] Y.H. Yun, V.T. Turitto, K.P. Daigle, P. Kovacs, J.A. Davidson, S.M. Slack. Initial hemocompatibility studies of titanium and zirconium alloys: Prekallikrein activation, fibrinogen adsorption, and their correlation with surface electrochemical properties. Journal of Biomedical Materials Research, 32, 77,1996.

[12] L.M. Elias , S.G. Schneider, S. Schneider, H.M. Silva, F. Malvisi, Microstructural and mechanical characterization of biomedical $\mathrm{Ti}-\mathrm{Nb}-\mathrm{Zr}(-\mathrm{Ta})$ alloys. Materials Science and Engineering A, 432, 108, 2006.

[13] Z.C. Zhoua, J.Y. Xiong, S.Y. Gu, D.K. Yang, Y.J. Yan, J. $\mathrm{Du}$. Anelastic relaxation caused by interstitial atoms in type sintered $\mathrm{Ti}-\mathrm{Nb}$ alloys. Journal of Alloys and Compounds, 509, 7356, 2011.

[14] C.A.C. Zavaglia, Uso de Biomateriais Cerâmicos em Próteses Ortopédicas. Tese de livre-docência, Unicamp,

1993.

[15] M. Niinomi. Mechanical Properties of Biomedical Titanium Alloys - Materials Science and Engineering, A 243, 231,1998 .

[16] M. Niinomi, D. Kuroda, Kei-ichi Fukunaga, M. Morinaga, Y. Kato, T. Yashiro, A. Suzuki, Corrosion wear fracture of new $\beta$ type biomedical titanium alloys. Materials Science and Engineering A, 263, 193, 1999.

[17] N.A. Al-Mobarak, A.A. Al-Swayih, F.A. Al-Rashoud, Corrosion behavior of Ti-6Al-7Nb alloy in biological solution for dentistry applications. International Journal of Electrochemical Science, 6, 2031, 2011.

[18] D.J. Blackwood, L.M. Peter, D.E. Williams, Stability and open circuit breakdown of the passive oxide film on titanium. Electrochimica Acta. 33, 1143, 1988.

[19] A.S. Mogoda, M.M. Hefny, S.A. Salih, H.E. El-Faiky. Electrochemical behaviour of surface zirconium oxides in the presence of some electroactive species. Thin Solid Films, 250, 87, 1994.

[20] Y.Z. Liu, X.T. Zu, C. Li, S.Y. Qiu, X.Q. Huang, L.M. Wang. Surface characteristics and corrosion behavior of $\mathrm{Ti}-\mathrm{Al}-\mathrm{Zr}$ alloy implanted with $\mathrm{Al}$ and $\mathrm{Nb}$. Corrosion Science. 49, $1069,2007$.

[21] A. Cremasco, W.R. Osório, C.M.A. Freire, A. Garcia, R. Caram. Electrochemical corrosion behavior of a $\mathrm{Ti}-35 \mathrm{Nb}$ alloy for medical prostheses. Electrochimica Acta. 53, 4867, 2008.

[22] S.J. Pang, C.H. Shek, K. Asami, A. Inoue, T. Zhang. Formation and corrosion behavior of glassy $\mathrm{Ni}-\mathrm{Nb}-\mathrm{Ti}-\mathrm{Zr}-$ $\mathrm{Co}(-\mathrm{Cu})$ alloys Journal of Alloys and Compound,. 434-435, 240, 2007.

[23] Ravi Shankar, R.K. Dayal, R. Balasubramaniam, V.R. Raju, R. Mythili, S. Saroja, M. Vijayalakshmi, V.S. Raghunathan. Effect of heat treatment on the corrosion behaviour of $\mathrm{Ti}-5 \mathrm{Ta}-1.8 \mathrm{Nb}$ alloy in boiling concentrated nitric acid. Journal of Nuclear Materials, 372, 277, 2008.

[24] M.T. Pham, I. Zyganow, W. Matz, H. Reuther, S. Oswald, E. Richter, E. Wieser, Corrosion behavior and microstructure of titanium implanted with $\alpha$ and $\beta$ stabilizing elements. Thin Solid Films, 310, 251, 1997.

[25] R. Mythili, S. Saroja, M. Vijayalakshmi, V.S. Raghunathan. Selection of optimum microstructure for improved corrosion resistance in a $\mathrm{Ti}-5 \% \mathrm{Ta}-1.8 \% \mathrm{Nb}$ alloy. Journal of Nuclear Materials, 345, 167, 2005.

[26] N.T.C. Oliveira, S.R. Biaggio, R.C. Rocha Filho, N. Bocchi, Corrosion resistance of anodic oxides on the $\mathrm{Ti}-50 \mathrm{Zr}$ and $\mathrm{Ti}-13 \mathrm{Nb}-13 \mathrm{Zr}$ alloys. Electrochimica. Acta, 51, 2068, 2006.

[27] A.I. Karayan, S.W. Park, K. M. Lee, Corrosion behavior of $\mathrm{Ti}-\mathrm{Ta}-\mathrm{Nb}$ alloys in simulated physiological media. Materials Letters, 62, 1843, 2008.

[28] S.L. Assis, S. Wolynec, I. Costa, Corrosion characterization of titanium alloys by electrochemical techniques. Electrochimica Acta, 51, 1815, 2006. 